\title{
BMJ Open Mediating effects of early health on the relationship between early poverty and long-term health outcomes of children: a birth cohort study
}

Wan-Lin Chiang, ${ }^{1}$ Tung-liang Chiang (D) ${ }^{2}$

To cite: Chiang W-L, Chiang T. Mediating effects of early health on the relationship between early poverty and long-term health outcomes of children: a birth cohort study. BMJ Open 2021;11:e052237. doi:10.1136/ bmjopen-2021-052237

- Prepublication history and additional supplemental material for this paper are available online. To view these files, please visit the journal online (http://dx.doi.org/10.1136/ bmjopen-2021-052237).

Received 09 April 2021 Accepted 26 November 2021

Check for updates

(C) Author(s) (or their employer(s)) 2021. Re-use permitted under CC BY-NC. No commercial re-use. See rights and permissions. Published by BMJ.

${ }^{1}$ Department of Health and Welfare, University of Taipei, Taipei, Taiwan

${ }^{2}$ Institute of Health Policy and Management, National Taiwan University, Taipei, Taiwan

Correspondence to Professor Tung-liang Chiang; tlchiang@ntu.edu.tw

\section{ABSTRACT}

Objective This study analyses the mediating effects of early health prior to age 3 on the association between early poverty and the health outcomes of children at age 12.

Design Population-based longitudinal birth cohort study. Setting Taiwan Birth Cohort Study (TBCS), 2005-2017. Participants 16847 TBCS children born in 2005 and followed up at 18 months, 3, 5, 8 and 12 years with available data on poverty and health status.

Main outcome measures Child's general health, measured by the mothers' ratings of their child's health, and hospitalisation experience at 12 years of age.

Results Among the TBCS children, the prevalence of fair/poor health and hospitalisation was $20.8 \%$ and $2.5 \%$ at age 12. The ORs of experiencing fair/poor health and hospitalisation at age 12 were $1.33(95 \% \mathrm{Cl} 1.21$ to 1.45$)$ and 1.35 (1.07 to 1.69) for early poverty, respectively. When early poor health was added in the multiple logistic regression models, the effects of early poverty were attenuated on poor general health and no longer significant on hospitalisation for children aged 12 years. Mediation analysis showed that $50 \%-87 \%$ of the total effect of early poverty on health at age 12 was mediated by early health status before age 3 .

Conclusions Our findings suggest that poor health in early life plays as a significant mediator in the relationship between early poverty and the long-term health outcomes of children. Universal health coverage thus should be achieved to prevent the adverse health effects of poverty throughout the life course, as one of the most important strategies for children growing up in poverty.

\section{INTRODUCTION}

Nearly one in three children around the world live in poverty. ${ }^{1}$ Poverty exposure in early life is an important factor for poor health in childhood..$^{2-4}$ Children living in poverty frequently have little access to nutritious foods, safe water, sanitation facilities, shelter and healthcare, which renders them more vulnerable to illness and disease. ${ }^{56}$ Empirical studies have demonstrated that poor children have a higher risk of experiencing adverse health
Strengths and limitations of this study

This is the first study designed to explore the mediating effects of general health in early life on the association between early poverty and later health of children in Asia.

- This study included 16847 children from the population-based longitudinal birth cohort study in Taiwan, with information on poverty and health conditions at baseline and 12-year follow-up.

- We measured two types of general health indicators of children, considering both objective and subjective aspects of health to ensure that our findings are robust.

- Lack of information on biological factors and biomarkers which would allow the exploration of the epigenetic mechanisms for biological and environmental interactions in early life.

outcomes and death than their less impoverished peers. ${ }^{7-11}$

Health conditions during the crucial early childhood period shape lifelong health. ${ }^{12}$ Since the Barker hypothesis was first introduced in the 1990s, the long-term effects of early developmental experiences on health and disease risk into adulthood have been recognised and investigated. ${ }^{13-16}$ As a result, the WHO has adopted a life course approach for the prevention and control of noncommunicable diseases. ${ }^{17-19}$ With the launch of the Sustainable Development Goals in 2015, the United Nations further proposed updated global strategies to improve women's, children's and adolescents' health by taking a life-course approach. ${ }^{20}$

However, early poverty, early health conditions and long-term health outcomes of children have rarely been examined at the same time. ${ }^{21-23}$ According to the life course perspective, different socioeconomic statuses in early years may result in various health trajectories in early childhood that in turn affect children's future health status. ${ }^{24}$ In this 


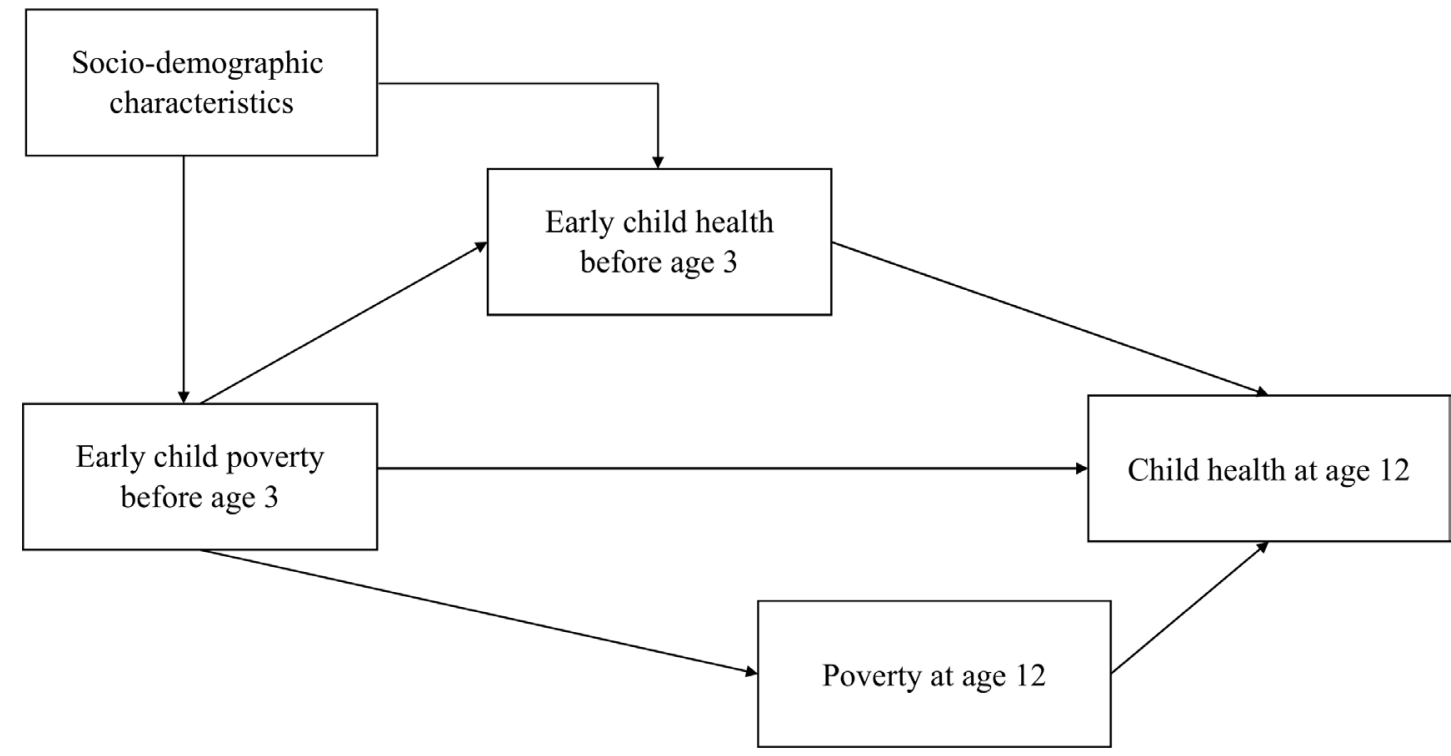

Figure 1 Conceptual model.

study, we aimed to examine the mediating effects of early health conditions on the relationship between poverty status prior to age 3 and the health outcomes of children up to age of 12 by using data from a nationwide, longitudinal birth cohort study in Taiwan. Figure 1 presents the conceptual framework of this study.

\section{METHODS}

\section{Study population}

The Taiwan Birth Cohort Study (TBCS) is a nationally representative, longitudinal cohort study of children in Taiwan. Details of the objectives, design, instruments and sample characteristics of the TBCS have been described in a previous publication. ${ }^{25}$ The cohort consists of 21248 babies born in 2005 and data collection began with a faceto-face interview by trained staff with the mother at the child's age of 6 months. Five waves of follow-up surveys were conducted at 18 months, 3 years, 5 years, 8 years and 12 years of age. Retention rates were $94.9 \%, 93.7 \%$, $92.8 \%, 91.8 \%$ and $88.5 \%$, respectively, for the follow-up surveys. A total of 16847 children who completed all 6 waves of TBCS surveys were included in our analysis, with data available for analyses including family poverty status and the child's health status.

\section{Health outcomes}

Health outcomes in this study included the child's general health and hospitalisation (described below) at 12 years of age. Children's general health status was rated by the mother with one question: 'Would you say your child's health in general, is very good, good, fair, poor, or very poor?' Responses were dichotomised as fair/ poor (fair, poor, or very poor) versus good (very good or good). Children's hospitalisation was measured with one question: 'Whether the child has been hospitalised in the previous year?' and was classified as yes versus no.

\section{Early poverty and early poor health}

We investigated early poverty and early poor health as primary predictors of subsequent health outcomes. Early poverty was defined as a child having lived before age three in a family with a monthly income of less than New Taiwan dollars (NT\$) 30000 (about US\$1000 or Great Britain pound (GBP) 750). Children with fair/ poor general health before age 3 and having been hospitalised at any time from birth to age 3 years were used as indicators of early poor health. The distribution of diagnoses for children's hospitalisation using the International Classification of Diseases (ICD) codes is provided in online supplemental appendix 1. In addition, under the National Health Insurance, all children in Taiwan have equal access to healthcare with a moderate cost sharing. ${ }^{2627}$

\section{Covariates}

Covariates of our study included child and maternal characteristics correlated with child health, with data collected at 6 months of age. Child characteristics included sex, birth order, low birth weight (infants born weighing $<2500 \mathrm{~g}$ ), preterm (infants born after $<37$ gestation weeks) and predominant breast feeding. Predominant breast feeding was defined as infants who were predominantly breastfed for more than 120 days after birth. ${ }^{28}$ Maternal characteristics included mother's age at the child's birth (less than 25 years, 25-29 years, 30-34 years and greater than 35 years), maternal nationality (Taiwanese vs foreign-born (China, Southeast Asia or others)) and the mother's level of education (junior high school or below, senior high school and college and above). Further, considering the health facilities and the utilisation of healthcare may vary across regions, we included children's residential locality at 6 months of age as covariates. Residential locality was categorised as rural and urban according to the definition of administrative divisions in Taiwan. We also controlled 
Table 1 Baseline characteristics of participants in the Taiwan Birth Cohort Study children

\section{Fair/poor health at 12 years} of age

\begin{tabular}{|c|c|c|c|c|c|c|c|}
\hline \multirow[b]{3}{*}{ Characteristics } & \multirow[b]{2}{*}{ All } & & & & \multirow[b]{3}{*}{$P$ value } \\
\hline & & No & Yes & & No & Yes & \\
\hline & N (\%) & n (\%) & n (\%) & $P$ value & n (\%) & n (\%) & \\
\hline Total & $16847(100.0)$ & $13340(79.2)$ & 3507 (20.8) & & 16432 (97.5) & $415(2.5)$ & \\
\hline
\end{tabular}

Poverty status

Early child poverty

No

Yes

Poverty at age 12

No

Yes $16847(100.0)$ $13340(79.2) \quad 3507(20.8)$

Child hospitalisation at 12 years of age

\section{Child characteristics}

Sex

\begin{tabular}{|c|c|c|c|c|c|c|c|}
\hline Girl & $8000(47.5)$ & $6358(79.5)$ & $1642(20.5)$ & & $7832(97.9)$ & $168(2.1)$ & \\
\hline Boy & 8847 (52.5) & 6982 (78.9) & 1865 (21.1) & & 8600 (97.2) & 247 (2.8) & \\
\hline Birth order & & & & 0.003 & & & 0.788 \\
\hline First & $8432(50.1)$ & $6598(78.3)$ & $1834(21.7)$ & & 8227 (97.6) & 205 (2.4) & \\
\hline $\begin{array}{l}\text { Second and } \\
\text { higher }\end{array}$ & 8415 (49.9) & $6742(80.1)$ & $1673(19.9)$ & & 8205 (97.5) & $210(2.5)$ & \\
\hline Low birth weight & $1135(6.7)$ & $836(73.7)$ & $299(26.3)$ & $<0.001$ & $1101(97.0)$ & $34(3.0)$ & 0.231 \\
\hline Preterm & $1397(8.3)$ & $1063(76.1)$ & 334 (23.9) & 0.003 & $1354(96.9)$ & $43(3.1)$ & 0.122 \\
\hline $\begin{array}{l}\text { Predominant breast } \\
\text { feeding }\end{array}$ & $2637(15.6)$ & $2138(81.1)$ & 499 (18.9) & 0.009 & $2563(97.2)$ & $74(2.8)$ & 0.216 \\
\hline \multicolumn{8}{|c|}{ Maternal characteristics } \\
\hline $\begin{array}{l}\text { Age at birth of the } \\
\text { child (years) }\end{array}$ & & & & 0.021 & & & 0.753 \\
\hline$\leqq 24$ & 2289 (13.6) & 1759 (76.9) & 530 (23.2) & & $2230(97.4)$ & $59(2.6)$ & \\
\hline $25-29$ & $5511(32.7)$ & $4370(79.3)$ & $1141(20.7)$ & & 5367 (97.4) & $144(2.6)$ & \\
\hline $30-34$ & $6143(36.5)$ & $4910(79.9)$ & $1233(20.1)$ & & $6000(97.7)$ & $143(2.3)$ & \\
\hline$\geqq 35$ & $2904(17.2)$ & $2301(79.2)$ & $603(20.8)$ & & 2835 (97.6) & $69(2.4)$ & \\
\hline Nationality & & & & 0.134 & & & 0.039 \\
\hline Taiwanese & $14836(88.1)$ & $11722(79.0)$ & $3114(21.0)$ & & $14484(97.6)$ & $352(2.4)$ & \\
\hline Foreign-born & 2011 (11.9) & $1618(80.4)$ & $393(19.6)$ & & 1948 (96.9) & $63(3.1)$ & \\
\hline Education & & & & 0.054 & & & 0.001 \\
\hline $\begin{array}{l}\text { @Junior high } \\
\text { school }\end{array}$ & $2230(13.2)$ & $1728(77.5)$ & 502 (22.5) & & 2155 (96.6) & $75(3.4)$ & \\
\hline $\begin{array}{l}\text { Senior high } \\
\text { school }\end{array}$ & 6705 (39.8) & $5298(79.0)$ & $1407(21.0)$ & & $6528(97.4)$ & 177 (2.6) & \\
\hline$\geqq$ College & 7912 (46.9) & $6314(79.8)$ & $1598(20.2)$ & & 7749 (97.9) & $163(2.1)$ & \\
\hline Residential locality & & & & 0.179 & & & 0.146 \\
\hline Urban & $11986(71.2)$ & $9523(79.4)$ & $2463(20.6)$ & & 11704 (97.6) & $282(2.3)$ & \\
\hline Rural & $4861(28.8)$ & 3817 (78.5) & $1044(21.5)$ & & 4728 (97.3) & $133(2.7)$ & \\
\hline
\end{tabular}


Table 2 Bivariate correlation between early poverty and early poor health prior to age 3

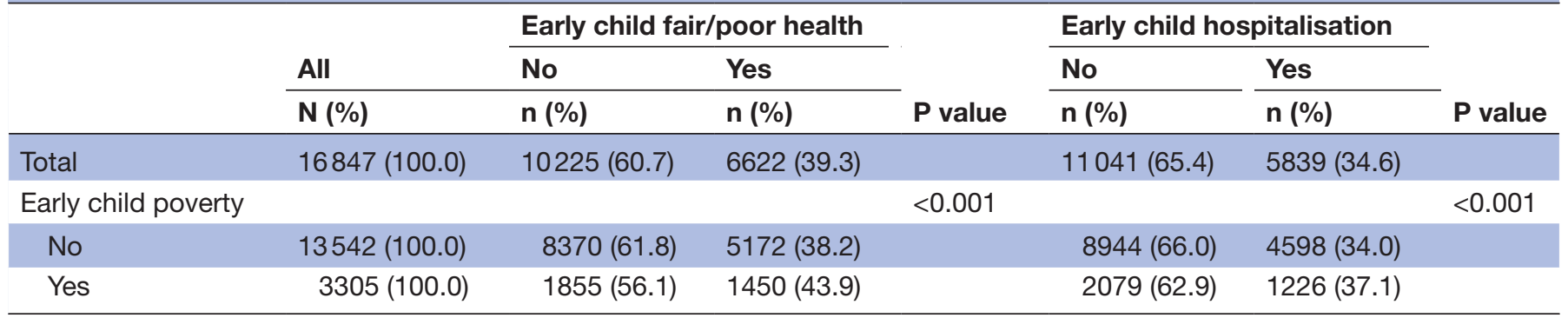

for concurrent family poverty status when the child's health status was measured at 12 years of age.

\section{Statistical analysis}

We conducted a $\chi^{2}$ test to assess potential differences in demographic characteristics between children who had poor and good health outcomes at 12 years of age. Next, we used logistic regression to explore the data for the associations between early poverty, early poor health and child health outcomes. Further, the causal mediation analysis was undertaken to compute the standardised estimates to assess the direct effect, indirect effect, total effect and the proportion mediated via early health conditions and current poverty for the relationships of early poverty and health outcomes, while adjusting for the covariates. ${ }^{29}$ All analyses were conducted using SAS software V.9.4 (SAS Institute).

\section{RESULTS}

\section{Sociodemographic characteristics}

Table 1 shows the sociodemographic characteristics of the TBCS children and their relationship with children's health outcomes at 12 years of age. Of the 16847 children included in the study, $19.6 \%$ and $10.3 \%$ experienced poverty during the first 3 years of life and at age 12 years, respectively, $52.5 \%$ were boys, $50.1 \%$ were firstborn, $6.7 \%$ were born weighing less than $2500 \mathrm{~g}, 8.3 \%$ were born before 37 weeks' gestation and $15.6 \%$ received breast milk as the predominant source of nourishment more than 120 days after birth.

Overall, 20.8\% $(n=3507)$ and $2.5 \% \quad(n=415)$ of the children were reported to be in fair/poor health and hospitalised at age 12, respectively. Children living in poverty, being first-born, low birth weight, preterm, nonpredominantly breastfed and born to mothers under 24 years of age were more likely to be in fair/poor health at age 12. Children who experienced early poverty, were boys, had foreign-born or mothers with low-level education were more likely to be hospitalised at age 12 .

\section{Early poverty and early poor health}

Of the children in our study, 39.3\% (n=6622) had fair/ poor health and $34.6 \%(n=5839)$ were hospitalised at least once during their first 3 years of life (table 2). Early poverty was linked to higher rates of early child fair/poor health and early child hospitalisation (both $\mathrm{p}<0.001$ ).
Early poverty, early poor health and child general health

Table 3 shows that general health at age 12 was significantly associated with both poverty and poor health in early life $($ all $\mathrm{p}<0.001)$. Compared with children who did not experience poverty early in life, children who did were much more likely to have poorer health at age 12 (24.7\% vs $19.9 \%$, crude OR 1.33 , $95 \%$ CI 1.21 to 1.45 ). Similarly, children who had been in fair/poor health (30.8\% vs $14.3 \%$, crude OR $2.67,95 \%$ CI 2.47 to 2.88 ) or hospitalised ( $23.4 \%$ vs $19.5 \%$, crude OR $1.27,95 \%$ CI 1.17 to 1.37 ) prior to age 3 had poorer general health at age 12 , compared with children who had never been in fair/ poor health or hospitalised prior to age 3 , respectively.

The direct effects of early poverty on children's general health at age 12 were slightly attenuated as early health status was added in the multiple logistic regression models. As shown in model 1 and model 2 of table 3, both early child fair/poor health and early child hospitalisation can predict fair/poor general health in later childhood. In addition, model 3 and model 4 indicate that the effects of early poverty were reduced substantially, after controlling for current poverty. Model 5 shows that the results remained significant even after adjusting for early poverty, early child fair/poor health, early child hospitalisation and current poverty simultaneously.

\section{Early poverty, early poor health and child hospitalisation}

Generally, the effects of early poverty and early poor health on child hospitalisation were similar to the effects on child general health. Children who had experienced poverty and poor health early in life had higher rates of hospitalisation at age 12 (table 4 ). The hospitalisation rate at age 12 was $3.1 \%$ for children experiencing early poverty, compared with $2.3 \%$ for children not experiencing early poverty (crude OR 1.35, 95\% CI 1.07 to 1.69 ), and the hospitalisation rate was $2.8 \%$ for children with early fair/ poor health, compared with $2.3 \%$ for children reported to be in good health during the first 3 years of life (crude OR $1.24,95 \%$ CI 1.02 to 1.51 ). The similar figures for the crude ORs of being hospitalised at age 12 were $1.60(95 \%$ CI 1.32 to 1.95 ) for early child hospitalisation.

Although a similar pattern of results also emerged in multiple logistic regression models, the relationships between early poverty and child hospitalisation at age 12 were no longer significant when the covariates were considered simultaneously. There was no significant 


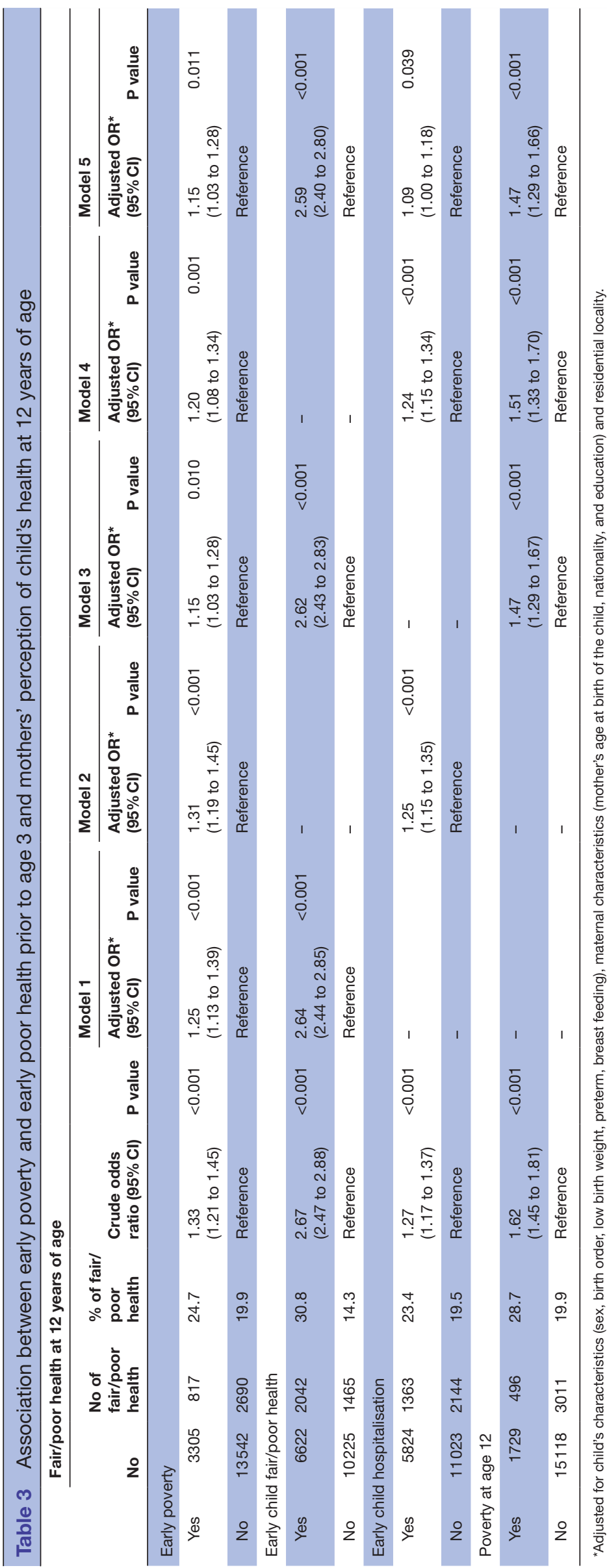

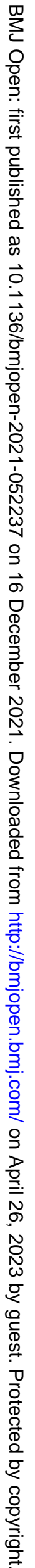




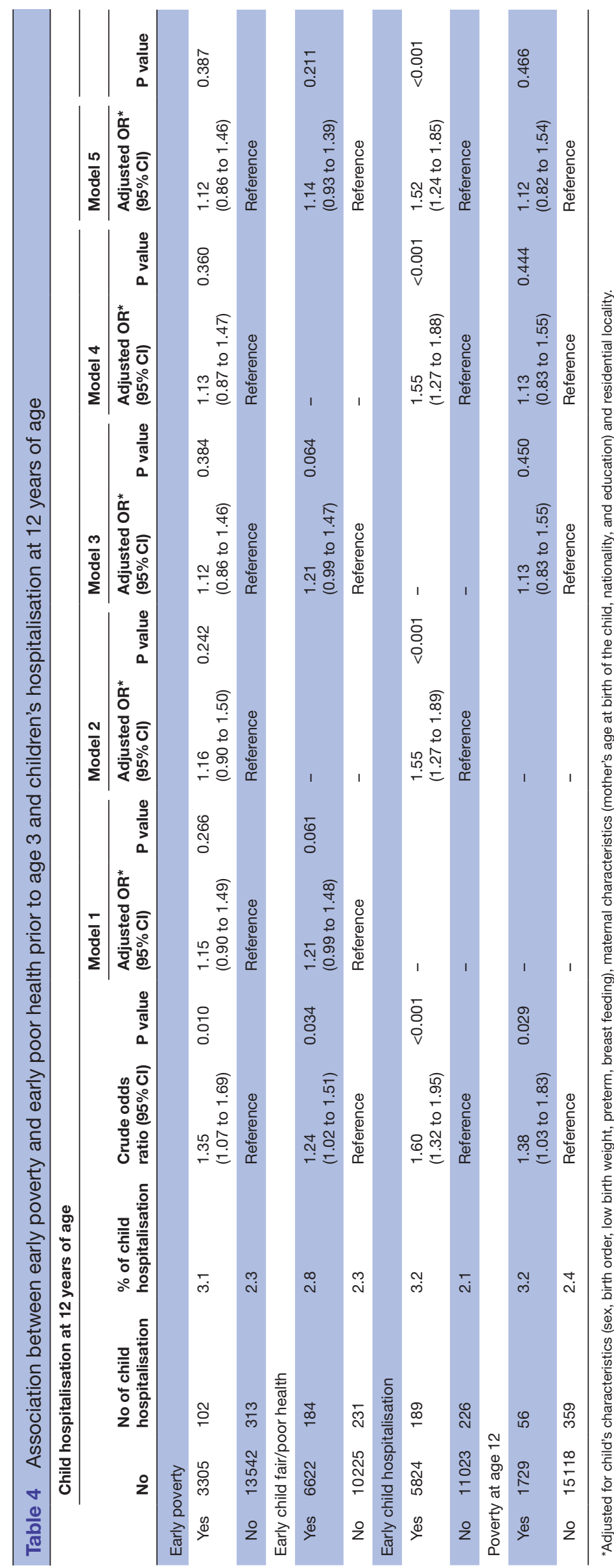

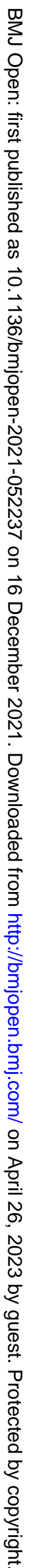


Table 5 Mediating effects on the association between early poverty prior to age 3 and the health outcomes of children at age 12

\begin{tabular}{|c|c|c|c|c|c|}
\hline Health outcomes & $\begin{array}{l}\text { Indirect } \\
\text { (mediated) } \\
\text { effect }\end{array}$ & $\begin{array}{l}\text { Direct effect } \\
\text { of early child } \\
\text { poverty }\end{array}$ & $\begin{array}{l}\text { Total effect } \\
\text { (direct plus } \\
\text { indirect) }\end{array}$ & $\begin{array}{l}\text { Proportion of } \\
\text { total effect } \\
\text { mediated (\%) }\end{array}$ & $\begin{array}{l}\text { Ratio of } \\
\text { indirect } \\
\text { to direct }\end{array}$ \\
\hline \multicolumn{6}{|l|}{ Child fair/poor health at age 12} \\
\hline Early child fair/poor health as mediator & 0.315 & 0.046 & 0.361 & 87.37 & 6.91 \\
\hline Early child hospitalisation as mediator & 0.060 & 0.060 & 0.120 & 50.04 & 1.00 \\
\hline Early child fair/poor health as mediator & 0.078 & 0.061 & 0.139 & 56.36 & 1.29 \\
\hline Early child hospitalisation as mediator & 0.121 & 0.061 & 0.182 & 66.37 & 1.97 \\
\hline Current poverty at age 12 as a mediator & 0.035 & 0.052 & 0.087 & 40.06 & 0.67 \\
\hline
\end{tabular}

association between early fair/poor general health and child hospitalisation at age 12 when early poverty status was considered together (model 1: adjusted OR 1.21, $95 \%$ CI 0.99 to 1.48 ), while the effect of early child hospitalisation remained strong on child hospitalisation at age 12 after controlling for early poverty, current poverty and early child fair/poor health (model 5: adjusted OR 1.52, $95 \%$ CI 1.24 to 1.85 ).

\section{Mediation effects}

For the mediation effects, this study builds two pathways of the impact of early poverty on later health of children. One is through early health conditions prior to age 3 and the other is through current poverty at age 12 .

First, we found that early health conditions substantially mediated the relationship between early child poverty and child health outcomes at age 12 (table 5). The proportion of the total effect of early child poverty on child fair/ poor health at age 12 mediated by early child fair/poor health was $87.3 \%$, and the proportion was $50.0 \%$ while early child hospitalisation was used as a mediator. Early child fair/poor health and early child hospitalisation also mediated the association between early child poverty and child hospitalisation at age 12 . Less than half of the total effects of early child poverty on child hospitalisation at age 12 occurred directly via early child poverty, whereas $56.3 \%$ and $66.3 \%$ of the effects occurred through early child fair/poor health and early child hospitalisation, respectively.

Second, our results also revealed that early poverty can affect child health outcomes through current poverty at age 12. The indirect effects through current poverty accounted for $40 \%-60 \%$ of the total effect of early child poverty on child fair/poor health and child hospitalisation at age 12 .

\section{DISCUSSION}

\section{Principal findings}

Using data from the TBCS, we discovered that both early poverty and early poor health have significant negative effects on the health of school-aged children. However, the effect of early poverty was attenuated when early health conditions were considered simultaneously as predictors of children's later health, indicating that children experiencing early poverty tend to have poor health prior to age 3 which results in long-term adverse health outcomes for children at age 12 .

\section{Strengths and weaknesses of the study}

There are two main strengths of this study. First, the use of a large population-based birth cohort study with a long follow-up period revealed the temporal relationship of early poverty and health outcomes in middle childhood and provides insight regarding the pathway through early poor health. Furthermore, the large sample size provided enough statistical power for the analysis of rare events among various subgroups, such as the hospitalisation rates of poor and non-poor children. Second, we measured two types of general health indicators of children, considering both objective (child hospitalisation) and subjective (motherreported child health status) aspects of health, to ensure that our findings are robust. However, this study has some limitations. There is lack of information on biological factors and biomarkers which would allow the exploration of the epigenetic mechanisms for biological and environmental interactions in early life. Moreover, as cohort studies are observational, children are not randomly assigned to poor and non-poor families in early childhood. Although we have controlled sociodemographic variables and change in poverty status in our analysis, ${ }^{8} 30$ it is not always possible to consider all relevant confounders. Hence, we should be very cautious when making causal inferences of early poverty, early poor health and later health in this study.

\section{Comparison with other studies and interpretation of the} results

Our data indicate that $34.6 \%$ of children have been hospitalised at least once by the age of 3 , and respiratory 
symptoms, infection and digestive disorders were the most leading causes, which is in accordance with the rate of child hospitalisation in Taiwan. ${ }^{31}$ Consistent with the findings of other studies, the results of this study also revealed that child hospitalisation was associated with low socioeconomic status. ${ }^{3233}$ Guttmann $e t a l^{32}$ found that low income adequacy was statistically significant related to the risk of hospitalisation. The study conducted in Taiwan also revealed that children living in poverty had higher hospital admission rates and lengths of stays for acute injuries, poisonings and lower respiratory infections than high-income children. $^{34}$

Importantly, the present results lend some credence to the developmental origins of health and disease hypothesis that health status during the first 3 years of life is negatively influenced by early poverty status and sets a foundation for the development of subsequent health status. ${ }^{152435}$ Previous research indicates specific biological processes to explain how environmental insults during early life, such as undernutrition or maternal stress, exert their programming effects, including changes in cell allocation, organ structure or the activity of the neuroendocrine system, and lead to permanent health problems in future life. ${ }^{1536}$ However, most previous studies were based on animal models, and thus, the biological mechanisms that link early poverty to later health outcomes in humans are mostly undiscovered. ${ }^{15}$

\section{CONCLUSION}

Early poverty is a crucial social determinant of child health. Our findings suggest that poor health in early life plays as a significant mediator in the relationship between early poverty and the long-term health outcomes throughout the life course. Universal health coverage thus should be achieved to prevent and mitigate the adverse health effects of poverty, as one of the most important strategies for children growing up in poverty.

Acknowledgements This study is based on longitudinal data from the Taiwan Birth Cohort Study, of which T-IC is the principal investigator. We gratefully acknowledge the financial and administrative support from the Health Promotion Administration, Ministry of Health and Welfare, and the time and continuing support from the participating families of the Taiwan Birth Cohort Study.

Contributors W-LC conceived the study, analysed the data, interpreted the results, drafted and revised the manuscript. T-IC conceived the study, interpreted the results and revised the manuscript. All authors approved the final manuscript as submitted and agree to be accountable for all aspects of the work. T-IC is the author responsible for the overall content as the guarantor.

Funding This study was financially supported by the Health Promotion Administration, Department of Health and Welfare (DOH 94-HP-1802, DOH 95-HP1802, DOH 96-HP-1702, DOH 99-HP-1702, DOH 102-HP-1701, MOHW106HPA-M-114-114701) and the Ministry of Science and Technology (MOST 106-2314-B-002-094-MY2) in Taiwan.

Disclaimer The funders were not involved in the research and preparation of the article, including in the study design, the analysis, and interpretation of data, the writing of the article, and the decision to submit the paper for publication.

Competing interests None declared.
Patient consent for publication Not applicable.

Ethics approval The study was approved by the Institutional Review Board at National Taiwan University Hospital (reference number 201612181RIND).

Provenance and peer review Not commissioned; externally peer reviewed.

Data availability statement № data are available.

Supplemental material This content has been supplied by the author(s). It has not been vetted by BMJ Publishing Group Limited (BMJ) and may not have been peer-reviewed. Any opinions or recommendations discussed are solely those of the author(s) and are not endorsed by BMJ. BMJ disclaims all liability and responsibility arising from any reliance placed on the content. Where the content includes any translated material, BMJ does not warrant the accuracy and reliability of the translations (including but not limited to local regulations, clinical guidelines, terminology, drug names and drug dosages), and is not responsible for any error and/or omissions arising from translation and adaptation or otherwise.

Open access This is an open access article distributed in accordance with the Creative Commons Attribution Non Commercial (CC BY-NC 4.0) license, which permits others to distribute, remix, adapt, build upon this work non-commercially, and license their derivative works on different terms, provided the original work is properly cited, appropriate credit is given, any changes made indicated, and the use is non-commercial. See: http://creativecommons.org/licenses/by-nc/4.0/.

\section{ORCID iD}

Tung-liang Chiang http://orcid.org/0000-0002-7876-3943

\section{REFERENCES}

1 UNICEF. Child poverty, 2019. Available: https://www.unicef.org/ social-policy/child-poverty [Accessed 5 Aug 2020].

2 Commission on Social Determinants of Health. Closing the gap in a generation: health equity through action on the social determinants of health. final report of the Commission on social determinants of health. Geneva: World Health Organization, 2008.

3 Council on Community Pediatrics. Poverty and child health in the United States. Pediatrics 2016;137:e20160339.

4 Walker SP, Wachs TD, Grantham-McGregor S, et al. Inequality in early childhood: risk and protective factors for early child development. Lancet 2011;378:1325-38.

5 Bellamy C. The state of the world's children 2005. New York: United Nations Children's Fund, 2004.

6 Victora CG, Wagstaff A, Schellenberg JA, et al. Applying an equity lens to child health and mortality: more of the same is not enough. Lancet 2003;362:233-41.

7 Chiang W-L, Chiang T-I. Region-specific child poverty and child mortality in Taiwan: 1980-2009. Taiwan J Public Health 2016;35:260-7.

8 Chiang W-L, Chiang T-I. Early poverty and children's general health at 8 years of age in the Taiwan Birth Cohort Study. Child Indic Res 2019;12:2067-77.

9 Egbuonu L, Starfield. Child health and social status. Pediatrics 1982;69:550-7.

10 Mare RD. Socioeconomic effects on child mortality in the United States. Am J Public Health 1982;72:539-47.

11 Newacheck PW. Poverty and childhood chronic illness. Arch Pediatr Adolesc Med 1994;148:1143-9.

12 Black MM, Walker SP, Fernald LCH, et al. Early childhood development coming of age: science through the life course. Lancet 2017;389:77-90.

13 Gluckman PD, Hanson MA, Cooper C, et al. Effect of in utero and early-life conditions on adult health and disease. $N$ Engl J Med 2008;359:61-73.

14 Barker DJ. Fetal origins of coronary heart disease. BMJ 1995;311:171-4.

15 Gluckman PD, Buklijas T, Hanson MA. The developmental origins of health and disease (DOHaD) concept: Past, present, and future. In: Rosenfeld C, ed. The epigenome and developmental origins of health and disease. Cambridge, MA: Academic Press Ltd, 2016.

16 Fleming TP, Watkins AJ, Velazquez MA, et al. Origins of lifetime health around the time of conception: causes and consequences. Lancet 2018;391:1842-52.

17 World Health Organization. Global action plan for the prevention and control of NCDs 2013-2020. Geneva: World Health Organization, 2013.

18 Mikkelsen B, Williams J, Rakovac I, et al. Life course approach to prevention and control of non-communicable diseases. BMJ 2019;364:1257. 
19 World Health Organization. The Minsk declaration: the life-course approach in the context of health 2020. World Health Organization, 2015.

20 United Nations. The Global Strategy for Women's, Children's and Adolescents' Health (2016-2030). Italy: Every Woman Every Child, 2015.

21 Case A, Lubotsky D, Paxson C. Economic status and health in childhood: the origins of the gradient. Am Econ Rev 2002;92:1308-34.

22 Straatmann VS, Lai E, Lange T, et al. How do early-life factors explain social inequalities in adolescent mental health? Findings from the UK millennium cohort study. J Epidemiol Community Health 2019;73:1049-60.

23 Yoshikawa H, Aber JL, Beardslee WR. The effects of poverty on the mental, emotional, and behavioral health of children and youth: implications for prevention. Am Psychol 2012;67:272-84.

24 Hertzman $C$. The biological embedding of early experience and its effects on health in adulthood. Ann N Y Acad Sci 1999;896:85-95.

25 Chang L-Y, Lin Y-H, Lin S-J, et al. Cohort profile: Taiwan birth cohort study (TBCS). Int J Epidemiol 2021:50:1430-1.

26 Chiang TL. Taiwan's 1995 health care reform. Health Policy 1997;39:225-39.

27 Cheng $\mathrm{SH}$, Chiang TL. The effect of universal health insurance on health care utilization in Taiwan. results from a natural experiment. JAMA 1997;278:89-93.

28 Wu W-c, Wu JC-L, Chiang T-I. Variation in the association between socioeconomic status and breastfeeding practices by immigration status in Taiwan: a population based birth cohort study. BMC Pregnancy Childbirth 2015;15:298.

29 SAS support: SAS customer support site. usage note 59081: mediation analysis. Available: https://support.sas.com/kb/59/081. html [Accessed 16 Jun 2020].

30 Chiang W-L, Chiang T-I. Risk factors for persistent child poverty during the first five years of life in Taiwan birth cohort study. Child Indic Res 2018;11:885-96.

31 Ministry of Health and Welfare. National health insurance statistics, 2019. Available: https://www.mohw.gov.tw/np-131-2.html [Accessed 6 Feb 2020].

32 Guttmann A, Dick P, To T. Infant hospitalization and maternal depression, poverty and single parenthood - a population-based study. Child Care Health Dev 2004;30:67-75.

33 Nikièma B, Zunzunegui MV, Séguin L, et al. Poverty and cumulative hospitalization in infancy and early childhood in the Quebec birth cohort: a puzzling pattern of association. Matern Child Health $J$ 2008;12:534-44.

34 Chen L, Lu H-M, Shih S-F, et al. Poverty related risk for potentially preventable hospitalisations among children in Taiwan. BMC Health Serv Res 2010;10:1-12.

35 Hertzman C, Power C. Child development as a determinant of health across the life course. Current Paediatrics 2004;14:438-43.

36 Bateson P, Barker D, Clutton-Brock T, et al. Developmental plasticity and human health. Nature 2004;430:419-21. 